\title{
Association of the C47T Polymorphism in SOD2 with Amnestic Mild Cognitive Impairment and Alzheimer's Disease in Carriers of the APOE\&4 Allele
}

\author{
David Gamarra, ${ }^{1}$ Xabier Elcoroaristizabal, ${ }^{1}$ \\ Manuel Fernández-Martínez, ${ }^{2}$ and Marian M. de Pancorbo ${ }^{1}$ \\ ${ }^{1}$ BIOMICS Research Group, Department of Zoology and Cellular Biology A, Lascaray Research Center (CIEA), \\ University of the Basque Country (UPV/EHU), Vitoria-Gasteiz, 01006 Alava, Spain \\ ${ }^{2}$ Department of Neurology, Hospital Universitario Cruces, BioCruces Health Research Institute, Barakaldo, 48093 Bizkaia, Spain
}

Correspondence should be addressed to Marian M. de Pancorbo; marian.mdepancorbo@ehu.eus

Received 12 July 2015; Revised 12 November 2015; Accepted 17 November 2015

Academic Editor: Fabrizia Bamonti

Copyright (C) 2015 David Gamarra et al. This is an open access article distributed under the Creative Commons Attribution License, which permits unrestricted use, distribution, and reproduction in any medium, provided the original work is properly cited.

Oxidative stress plays an important part in amnestic mild cognitive impairment (aMCI), the prodromal phase of Alzheimer's disease (AD). Recent evidence shows that polymorphisms in the SOD2 gene affect the elimination of the reactive oxygen species (ROS) generated in mitochondria. The aim of this study was to determine whether the functional rs4880 SNP in the SOD2 gene is a risk factor associated with aMCI and sporadic AD. 216 subjects with aMCI, 355 with AD, and 245 controls have been studied. The SNP rs4880 of the SOD2 gene was genotyped by RT-PCR and the APOE genotype was determined by PCR and RFLPs. Different multinomial logistic regression models were used to determine the risk levels for aMCI and AD. Although the T allele of the SOD2 rs4880 SNP gene (rs4880-T) is not an independent risk for aMCI or AD, this allele increases the risk to aMCI patients carrying at least one APOE $\varepsilon 4$ allele. Moreover, rs4880-T allele and APOE 44 allele combination has been found to produce an increased risk for AD compared to aMCI reference patients. These results suggest that APOE 44 and rs4880-T genotype may be a risk for aMCI and a predictor of progression from aMCI to AD.

\section{Introduction}

Neuropathologically, the accumulation of beta-amyloid $(\mathrm{A} \beta)$ and tau proteins in the brain tissue of patients with Alzheimer's disease $(\mathrm{AD})$ is related to the loss of synapse and neuronal death. The increase in oxidative stress seems to be one of the possible causes of the aetiology of $\mathrm{AD}$, probably due to the loss of physiological control of the reactive oxygen species (ROS) [1]. Animal models have allowed correlating the increase in oxidative stress to the increase in the levels and plaques of $\mathrm{A} \beta$ and oxidative damage [2]. Moreover, a prodromal phase of $\mathrm{AD}$, amnestic mild cognitive impairment (aMCI), has been accepted as a transition phase between normal aging and Alzheimer's disease (AD) [3, 4]. In fact, aMCI patients have shown a greater risk for developing $\mathrm{AD}$ and convert at an annual rate of $10 \%$ to $15 \%$, compared with $1 \%-2 \%$ in the general elderly population $[5,6]$. The brains of patients with $\mathrm{AD}$ in its prodromal phase, with amnesiac mild cognitive impairment (aMCI), have shown significant oxidative damage [7-10] and it is suggested that this damage affects the nuclear DNA differently from the mitochondrial one, the latter being greater [11]. Peripheral oxidative stress biomarkers in $\mathrm{AD}$ patients have showed an increase in molecules such as carbonyl proteins [12], 3-nitrotyrosine [13], isoprostanes [14], DNA oxidation (8-oxoguanine) [15], and malonaldehyde (MDA) [16]. Furthermore, higher MDA and carbonyl protein levels have been found in MCI [16, 17] reporting a clear evidence of oxidative damage in mild cognitive impairment too.

Mitochondria generate a significant amount of ROS in normal activity. These are eliminated by antioxidant enzymes, such as manganese superoxide dismutase (MnSOD) $[18,19]$. Animal models have shown that there is a compensatory induction of $\mathrm{MnSOD}$ in response to an initial increase in 
oxidative stress, which protects neurons from $\mathrm{A} \beta$ toxicity [20, 21]. Nevertheless, continued exposure to oxidative damage can suppress expression of MnSOD causing cell death in mature neurons [22]. This may be related to insufficient protection to oxidative damage in the brain $[23,24]$. Additionally, MnSOD activity diminishes with age, in keeping with the progression from aMCI to $\mathrm{AD}$, leading to an increase in ROS and exacerbating the pathogenesis related to $\mathrm{AD}$ [25-27].

The SOD2 gene (6q25) encodes the MnSOD and has several single nucleotide polymorphisms (SNPs), among which rs4880 $(\mathrm{C} / \mathrm{T})$ is included (also designated as C47T, Ala16Val, Ala-9Val or A16V). The T allele of this SNP (rs4880$\mathrm{T}$ ) has been associated with changes in the activity of MnSOD as a result of modification to the mitochondrial targeting sequence (MTS) [18, 21, 28], which may play a part in neurodegenerative processes. The results of the studies of this polymorphism associated with neurodegenerative illnesses are diverse, probably due to the different involvement of the antioxidant enzymes in these illnesses [29-38]. Specifically, the rs4880-T allele has been associated with a greater risk of familial $\mathrm{AD}$ [39], while not seeming to change the risk of sporadic AD [40]. Nevertheless, to date, no study has evaluated the rs4880 SNP in aMCI patients.

Apolipoprotein E (apoE), the main susceptibility factor for aMCI and $\mathrm{AD}[41,42]$, also has antioxidant properties that vary depending on its isoforms E2 > E3 > E4 [43]. Additionally, there is a relationship between these apoE isoforms and certain antioxidant enzymes. Thus, in brain tissue from AD patients, the activities of catalase and glutathione peroxidase in carriers of the E4 isoform are reduced [44]. Moreover, AD patients with APOE4 had shown higher blood hydroxyl radical levels than those without this allele or nondemented subjects [45]. This suggests that this isoform interacts with the antioxidant systems, at least the cytoplasmic ones. The $\mathrm{E} 4$ isoform has also been related to mitochondrial dysfunction and neurotoxicity $[46,47]$. Nevertheless, the molecular mechanism responsible for the antioxidant capacity of apoE is still unknown [48].

The SOD2 SNP rs4880 and the APOE genotypes are related to the cell antioxidant activity. The sum of specific alleles in both genes could confer greater susceptibility to the development of $\mathrm{AD}$ from its prodromal stage, aMCI. The aim of this study was to find the effect of the presence of the $\mathrm{T}$ allele of SOD2 SNP rs4880 (rs4880-T) in combination with the APOE 4 allele on the risk of aMCI and AD. In order to do this, we have carried out the genotyping of $A P O E$ and SOD2 in a case-control study.

\section{Materials and Methods}

2.1. Subjects. 816 samples were collected at neurology services of various hospitals in the Basque Country and included in National DNA Bank (Genome Foundation Spain). Patients with aMCI were diagnosed according to the Petersen criteria. Patients considered to have aMCI should show impaired memory and any reduction in their functions should be confirmed by an informant, with less than 0.5 on the CDR scale and normal state in the performance of other cognitive functions and routine activities. The figures obtained were adjusted for age and level of education. The diagnosis of $\mathrm{AD}$ was based on the DSM IV and the NINCDS-ADRDA criteria for AD. Patients with a total score of less than 3 (1 and 2) on the CDR scale (mild to moderate dementia) were included. Healthy control subjects had to obtain a score of $0 \mathrm{CDR}$ within the normal range for their age and level of education in the psychometric tests. According to the test results, the participants were classified into the following groups: patients with aMCI $(n=216)$, patients with $\mathrm{AD}(n=$ $355)$, and healthy control subjects $(n=245)$. Additionally, the biochemical and neuroimaging criteria published in Martínez et al. (2009) were taken into account [49].

This study was approved by the Ethics Committee of Cruces Hospital (Barakaldo, Biscay) and was carried out in accordance with the Declaration of Helsinki on biomedical research involving human beings. Informed consent was obtained before the start of the genetic and clinical tests.

2.2. Genetic Analysis. Samples of peripheral blood were taken from all the individuals using Vacutainer tubes with EDTA anticoagulant. The DNA was extracted by proteolytic lysis and purified using phenol/chloroform followed by ethanol precipitation. Genetic analyses were carried out without prior knowledge of the diagnosis (aMCI, AD, and healthy controls). The rs4880 SNP was genotyped using a TaqMan allelic discrimination assay (AB C_8709053_10) on an ABI PRISM 7000 SDS. The thermocycling conditions were as follows: $95^{\circ} \mathrm{C} 10 \mathrm{~min}, 40$ cycles $95^{\circ} \mathrm{C} 15 \mathrm{sec}$, and $58^{\circ} \mathrm{C} 1 \mathrm{~min}$ $30 \mathrm{sec}$. APOE was amplified with the $112 \mathrm{~F}$ and $158 \mathrm{R}$ primers under the conditions described by Wilton and Lim [50]. The genotype was obtained by digestion of the PCR product with Hae II and Afl III restriction enzymes under the conditions described by Alvarez-Alvarez et al. [51].

2.3. Statistical Analysis. The one-way ANOVA test was used to observe the differences in the demographic variables of age and the MMSE scores. Levene test was applied for homoscedasticity test and Dunnett's T3 test was computed. The goodness of fit for the Hardy-Weinberg equilibrium was estimated using the exact test in Guo and Thompson (1992) [52] using the Genepop v4.0 program. The $G$-test was used to check the differences of allelic and genotypic distributions between the groups of patients and controls with Bonferroni correction. Power for Genetic Association Analyses (PGA) package [53] has been used to compute the power of this casecontrol study.

Diverse logistic regression models were examined using the SPSS v22.0 software. Models were run under the assumption of additive (AA versus Aa versus aa), dominant (AA versus $A a / a a)$, or recessive (AA/Aa versus aa) inheritance in $\mathrm{aMCI}$ and $\mathrm{AD}$. First, the risk of $\mathrm{APOE} \varepsilon 4$ allele was evaluated. Secondly, rs4880-T allele and rs4880 genotypes risks were evaluated. Finally, rs4880-T and APOE 44 interaction terms to test for epistatic effects were computed. Control subjects adjusted for age and sex were used as a reference category to evaluate $\mathrm{AD}$ and $\mathrm{aMCI}$ risk. In addition, $\mathrm{aMCI}$ was also used as a reference category to evaluate $\mathrm{AD}$ risk. The $p<0.05$ values were considered significant. 
TABLE 1: Demographic characteristics.

\begin{tabular}{lcc}
\hline Group & $n$ (Men/women) & Age $^{\mathrm{a}}$ \\
\hline aMCI & $216(84 / 132)$ & $72.02 \pm 7.88$ \\
AD & $355(103 / 252)$ & $75.03 \pm 7.70$ \\
Controls & $245(101 / 144)$ & $74.81 \pm 10.23$ \\
\hline
\end{tabular}

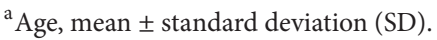

\section{Results}

The MMSE scores in the aMCI, AD, and control groups were $25.93 \pm 2.38,18.84 \pm 5.01$, and $28.05 \pm 1.56$, respectively. The comparison of averages in the MMSE showed statistically significant differences as expected.

Table 1 shows the age distribution and proportion of sexes in the three groups studied. The proportion of women was higher in all cases, with no statistically significant differences between aMCI and controls. In terms of the average age, no statistically significant differences were shown.

The allelic and genotypic frequencies of the SOD2 rs4880 SNP and the APOE gene of each groups studied are shown in Table 2. The $\mathrm{T}$ risk allele frequency of the rs4880 SNP was 0.488 for aMCI and 0.463 for $\mathrm{AD}$, being similar to the frequency observed in the controls (0.480). Therefore, significant differences between the aMCI, AD, and healthy control groups were not found in rs4880 polymorphism $(p>0.05)$. AD cases and controls fit the Hardy-Weinberg equilibrium (HWE) but not the aMCI group. A statistically significant deviation was found in aMCI cases due to a deficiency of CC homozygotes with a frequency of 0.218 being the frequency value expected of 0.259 .

APOE\&4 allele frequency was 0.250 in aMCI and 0.298 in $\mathrm{AD}$, being higher than frequency in controls (0.104). Controls did not show any $\varepsilon 4 \varepsilon 4$ genotype while a higher frequency in $\varepsilon 3 \varepsilon 4$ and $\varepsilon 4 \varepsilon 4$ genotypes was found in aMCI ( 0.305 and 0.093 , resp.) and $\mathrm{AD}$ (0.428 and 0.076 , resp.). These differences in $A P O E$ allelic and genotypic frequencies appeared to be statistically significant $(p<0.001)$ between aMCI versus controls and $\mathrm{AD}$ versus controls, although not between aMCI versus $A D$.

Multiple multinomial logistic regression analyses were carried out to check whether the rs 4880 allele is a risk factor for aMCI and AD using different models as shown in Table 3 (additive, CT versus CC and TT versus CC; dominant, $\mathrm{CT} / \mathrm{TT}$ versus $\mathrm{CC}$; and recessive, TT versus $\mathrm{CC} / \mathrm{CT}$ ). The odds ratio (OR) obtained was not significant in any of the models. None of the genotypes (TT and TC) of the rs 4880 SNP showed statistical significance, unlike the APOE 4 allele which was statistically significant (Table 3 ).

Subsequently, the epistatic effect of the rs4880-T and the APOE 4 alleles was evaluated (Table 3). To this end, the OR in carriers of the APOE\&4 allele and at least one rs4880-T allele was calculated and the results obtained were statistically significant. The risk for aMCI patients was nominally increased in carriers of APOE 4 allele combined with rs4880$\mathrm{T}$ allele in the dominant model $(\mathrm{OR}=3.17$; $95 \% \mathrm{CI}=1.80-$ 5.84, $p<0.001)$. Moreover, aMCI patients also showed an increased risk in carriers of the APOE 4 allele combined with
TC genotype in the additive model $(\mathrm{OR}=3.54 ; 95 \% \mathrm{CI}=1.82-$ $6.86, p<0.001)$. However, the epistatic effects of the rs 4880 $\mathrm{T}$ and the APOEc4 alleles have not shown an increased risk for Alzheimer's disease in comparison with results obtained considering only the APOE\&4 allele under different models and control patients as the reference category. On the other hand, when aMCI patients were used as the reference category, a significant risk for $\mathrm{AD}$ was observed in patients with APOE 4 allele $(\mathrm{OR}=1.64 ; 95 \% \mathrm{CI}=1.16-2.32, p<$ 0.001 ) and also an epistatic effect was observed for $\mathrm{AD}$ in carriers of the APOE 4 allele and the rs4880-TT genotype in the recessive model $(\mathrm{OR}=2.05 ; 95 \% \mathrm{CI}=1.09-3.87$, $p<0.001$ ) (Supplemental Table in Supplementary Material available online at http://dx.doi.org/10.1155/2015/746329).

\section{Discussion}

Oxidative stress is an age-related process that increases the risk of developing neurodegenerative illnesses. Various studies show the involvement of oxidative stress and mitochondrial dysfunction in neuronal injury and death, both during the initial stages of aMCI, and once AD has developed [54-57]. For this reason, the cellular processes involved in the detoxification of ROS have been considered of relevance to research into the factors of genetic susceptibility that promote cognitive impairment.

In our study, we have seen that the T allele of the SOD2 rs4880 SNP (rs4880-T) is more common in the aMCI group than in the healthy control group. Moreover, the aMCI group in particular does not comply with the Hardy-Weinberg equilibrium for this SNP, which seems to indicate a possible association between the rs4880-T allele and the disease. However, the absence of significant risk in the multinomial logistic regression models suggests that the rs4880-T allele is not a risk factor for $\mathrm{AMCI}$ and $\mathrm{AD}$. These results coincide with those of Ventriglia et al. [40] in AD patients, but it has not been possible to contrast them with aMCI due to the absence of prior studies.

Both SOD2 and APOE encode proteins with an antioxidant capacity $[18,41]$. For this reason, despite the lack of risk conferred by the rs4880-T allele, it is important to evaluate its interaction with the APOE 4 allele, because the combination of both alleles may increase the individual effects [58]. The instability of the mRNA product of the rs4880-T allele and the deficient amount to the mitochondrial matrix of the encoding isoform can negatively affect the formation of active SOD2 tetramer and, therefore, contribute to the increase of oxidative stress $[59,60]$. On the other hand, the rs4880-C allele allows a more efficient import to the mitochondrial matrix to form $40 \%$ more active tetramer than the rs $4880-\mathrm{T}$ allele [60].

Our results showed a slight nominal increase in the risk of only aMCI in carriers of the rs4880-T and APOE 4 alleles. Therefore, the results seem to indicate that the rs4880-T allele may be implicated in the increased risk of developing aMCI. This could be due to oxidative stress as an important factor in aMCI development but other neurodegenerative factors could also be responsible in the progression of healthy 
TABLE 2: Allelic and genotypic frequencies.

\begin{tabular}{|c|c|c|c|c|c|}
\hline Gene & & & $\operatorname{aMCI}(N=216)$ & $\mathrm{AD}(N=355)$ & Controls $(N=245)$ \\
\hline \multirow{6}{*}{ SOD2 } & \multirow{2}{*}{ Allele } & $\mathrm{T}$ & 0.488 & 0.463 & 0.480 \\
\hline & & $\mathrm{C}$ & 0.512 & 0.537 & 0.520 \\
\hline & \multirow{3}{*}{ Genotype } & $\mathrm{TT}$ & 0.194 & 0.220 & 0.221 \\
\hline & & $\mathrm{TC}$ & 0.588 & 0.487 & 0.518 \\
\hline & & CC & 0.218 & 0.293 & 0.261 \\
\hline & $\mathrm{H}-\mathrm{W}^{\mathrm{a}}$ & $p$-value ${ }^{\mathrm{b}}$ & 0.012 & 0.755 & 0.608 \\
\hline \multirow{10}{*}{$A P O E$} & \multirow{3}{*}{ Allele } & 2 & 0.025 & 0.034 & 0.057 \\
\hline & & 3 & 0.725 & 0.668 & 0.839 \\
\hline & & 4 & 0.250 & 0.298 & 0.104 \\
\hline & \multirow{6}{*}{ Genotype } & $2 / 2$ & 0.000 & 0.000 & 0.009 \\
\hline & & $2 / 3$ & 0.042 & 0.050 & 0.090 \\
\hline & & $2 / 4$ & 0.009 & 0.018 & 0.008 \\
\hline & & $3 / 3$ & 0.551 & 0.428 & 0.693 \\
\hline & & $3 / 4$ & 0.305 & 0.428 & 0.200 \\
\hline & & $4 / 4$ & 0.093 & 0.076 & 0.000 \\
\hline & $\mathrm{H}-\mathrm{W}^{\mathrm{a}}$ & $p$-value ${ }^{\mathrm{b}}$ & 0.115 & 0.567 & 0.087 \\
\hline
\end{tabular}

${ }^{\mathrm{a}}$ Hardy-Weinberg equilibrium. ${ }^{\mathrm{b}}$ Significative $p$ value $<0.025$ after Bonferroni correction.

TABLE 3: Multinomial logistic regression models of rs4880-T (SOD2) and APOE\&4 allele in aMCI and AD patients.

\begin{tabular}{|c|c|c|c|c|c|c|}
\hline Gene & & Model & $\begin{array}{c}\text { aMCI } \\
\text { OR CI 95\% }\end{array}$ & $p$ & $\begin{array}{c}\mathrm{AD} \\
\text { OR CI 95\% }\end{array}$ & $p$ \\
\hline$A P O E$ & & $\varepsilon 4(+)$ & $2.54(1.68-3.83)$ & $<0.001$ & $4.15(2.85-6.05)$ & $<0.001$ \\
\hline \multirow{4}{*}{ SOD2 } & Additive & $\mathrm{TT}$ & $1.03(0.59-1.80)$ & 0.914 & $0.91(0.57-1.46)$ & 0.708 \\
\hline & Additive & TC & $1.34(0.85-2.11)$ & 0.206 & $0.85(0.57-1.25)$ & 0.415 \\
\hline & Dominant & $\mathrm{TC} / \mathrm{TT}$ & $1.25(0.81-1.93)$ & 0.318 & $0.87(0.60-1.26)$ & 0.455 \\
\hline & Recessive & TT & $0.84(0.53-1.33)$ & 0.455 & $1.01(0.68-1.50)$ & 0.943 \\
\hline \multirow{4}{*}{$A P O E * S O D 2$} & Additive & $\varepsilon 4(+) * \mathrm{TC}$ & $3.54(1.82-6.86)$ & $<0.001$ & $3.48(1.94-6.27)$ & $<0.001$ \\
\hline & Additive & $\varepsilon 4(+) * \mathrm{TT}$ & $2.39(1.00-5.74)$ & 0.051 & $3.28(1.54-6.99)$ & 0.002 \\
\hline & Dominant & $\varepsilon 4(+) * \mathrm{TC} / \mathrm{TT}$ & $3.17(1.80-5.84)$ & $<0.001$ & $3.41(2.01-5.80)$ & $<0.001$ \\
\hline & Recessive & $\varepsilon 4(+) * \mathrm{TT}$ & $1.95(0.89-4.27)$ & 0.095 & $4.00(2.00-7.99)$ & 0.002 \\
\hline
\end{tabular}

Control subjects were the reference category in all models. OR, odds ratio. CI, confidence interval.

individuals to Alzheimer's disease. The strengths of our work are its multicentre nature and the inclusion of patients with aMCI, $\mathrm{AD}$, and healthy controls in the same study to investigate the association of the rs4880 SNP of the SOD2 gene for the first time, in both $\mathrm{AD}$ and $\mathrm{aMCI}$, the stage prior to AD. Thus, it has been possible to see that the risk of the combination of the rs $4880-\mathrm{T}$ and $\mathrm{APOE} \varepsilon 4$ alleles $(\mathrm{OR}=3.17)$ has been calculated with sufficient statistical power (90.9\%). An increased risk $(\mathrm{OR}=3.54)$ with sufficient statistical power (99.9\%) has also been observed in rs4880-TC genotype and carriers of $\mathrm{APOE} \varepsilon 4$ for $\alpha=0.05$. However, the risk of the rs $4880-\mathrm{TT}$ and APOE $\varepsilon 4$ combination could not be evaluated due to lack of statistical power (74.5\%).

MCI has become a deal of interest, partly because the identification of patients at an early stage of $\mathrm{AD}$ may enable the initiation of treatment strategies when they are most likely to be effective. Despite the numerous genetic studies of $\mathrm{AD}$, the influence of genetic variation on progression from $\mathrm{MCI}$ to $\mathrm{AD}$ has been poorly studied. Although $\mathrm{MCI}$ patients have shown an increased risk for Alzheimer's disease (AD) [61], it is known that APOE 4 4 is the strongest genetic risk for AD. Further analysis has revealed that MCI patients with an APOE 44 allele have twice $(-/ \varepsilon 4)$ and four times $(\varepsilon 4 / \varepsilon 4)$ higher risk to convert to $\mathrm{AD}$ than those without an $\mathrm{APOE} \varepsilon 4$ allele [62], whereas annual conversion rate to $\mathrm{AD}$ seems to be increased from $20 \%$, in non-APOE $\varepsilon 4$ carriers, to $32.5 \%$ in patients with $\mathrm{APOE} \varepsilon 4$ [63]. Therefore, the interaction of $\mathrm{APOE} \varepsilon 4$ with other genes may possibly increase the prognostic accuracy. Although we could not calculate conversion rates due to an absence in monitoring of patients, we considered risk for $\mathrm{AD}$ patients with $\mathrm{APOE} \varepsilon 4$ and $\mathrm{rs} 4880$ $\mathrm{T}$ compared with an aMCI reference group. We found a significant risk for $\mathrm{AD}$ in patients with APOE 4 allele (OR $=1.56$ ) compared with non-APOE $\varepsilon 4$ carriers. Moreover, an increased risk for $\mathrm{AD}$ in patients with $\mathrm{APOE} \varepsilon 4$ and rs4880TT genotype $(\mathrm{OR}=2.05)$ was found (statistical power $>80 \%)$, suggesting that an epistatic effect in those polymorphisms could increase risk to develop AD from aMCI patients. 
In conclusion, the rs4880-T allele of the SOD2 gene is not an independent risk factor for aMCI and $\mathrm{AD}$ patients, although this allele in combination with the APOE\&4 allele produces an increase in the risk for aMCI. Finally, rs4880-T allele and $\mathrm{APOE} \varepsilon 4$ allele combination has also been found to produce an increased risk for $\mathrm{AD}$ compared to aMCI patients. These data need to be confirmed in further studies, and as new susceptibility variant has been identified, it needs to be confirmed in more MCI studies taking into account timedependent progression to $\mathrm{AD}$.

\section{Conflict of Interests}

The authors declare that they have no conflict of interests regarding the publication of this paper.

\section{Acknowledgments}

This work was sponsored by grants from the Federación de Asociaciones de Familiares de enfermos de Alzheimer de Euskadi, Fondo de Investigación Sanitaria del Instituto Carlos III (Madrid), Pfizer Foundation, and Ayudas a la Investigación de la Obra Social de la Caja Vital Kutxa. The authors gratefully acknowledge the collaboration provided by DETCOGEN Study Team (L. Galdos Alcelay, F. Gómez Busto, E. Blanco Martin, I. Ugarriza Serrano, A. Molano Salazar, R. Bereincua Gandarias, S. Inglés Borda, JM. Uterga Valiente, B. Indakoetxea Juanbeltz, MA. Gómez Beldarraín, J. Moraza López, and M. Barandiarán Amillano). The authors are grateful to Maite Alvarez, Ph.D., for her technical and human support provided by the DNA Bank Service (SGIker) of the University of the Basque Country (UPV/EHU) and European funding (ERDF and ESF).

\section{References}

[1] R. S. Sohal, "Role of oxidative stress and protein oxidation in the aging process," Free Radical Biology and Medicine, vol. 33, no. 1, pp. 37-44, 2002.

[2] F. Li, N. Y. Calingasan, F. Yu et al., "Increased plaque burden in brains of APP mutant MnSOD heterozygous knockout mice," Journal of Neurochemistry, vol. 89, no. 5, pp. 1308-1312, 2004.

[3] R. C. Petersen, B. Caracciolo, C. Brayne, S. Gauthier, V. Jelic, and L. Fratiglioni, "Mild cognitive impairment: a concept in evolution," Journal of Internal Medicine, vol. 275, no. 3, pp. 214228, 2014

[4] R. C. Petersen, J. C. Stevens, M. Ganguli, E. G. Tangalos, J. L. Cummings, and S. T. DeKosky, "Practice parameter: early detection of dementia: mild cognitive impairment (an evidencebased review). Report of the Quality Standards Subcommittee of the American Academy of Neurology," Neurology, vol. 56, no. 9, pp. 1133-1142, 2001.

[5] A. Busse, A. Hensel, U. Gühne, M. C. Angermeyer, and S. G. Riedel-Heller, "Mild cognitive impairment: long-term course of four clinical subtypes," Neurology, vol. 67, no. 12, pp. 2176-2185, 2006.

[6] R. C. Petersen, "Mild cognitive impairment as a diagnostic entity," Journal of Internal Medicine, vol. 256, no. 3, pp. 183-194, 2004.
[7] M. A. Lovell and W. R. Markesbery, "Oxidatively modified RNA in mild cognitive impairment," Neurobiology of Disease, vol. 29, no. 2, pp. 169-175, 2008.

[8] W. R. Markesbery, R. J. Kryscio, M. A. Lovell, and J. D. Morrow, "Lipid peroxidation is an early event in the brain in amnestic mild cognitive impairment," Annals of Neurology, vol. 58, no. 5, pp. 730-735, 2005.

[9] A. Nunomura, P. I. Moreira, A. Takeda, M. A. Smith, and G. Perry, "Oxidative RNA damage and neurodegeneration," Current Medicinal Chemistry, vol. 14, no. 28, pp. 2968-2975, 2007.

[10] D. Praticò, “The neurobiology of isoprostanes and Alzheimer's disease," Biochimica et Biophysica Acta, vol. 1801, no. 8, pp. 930933, 2010.

[11] J. Wang, S. Xiong, C. Xie, W. R. Markesbery, and M. A. Lovell, "Increased oxidative damage in nuclear and mitochondrial DNA in Alzheimer's disease," Journal of Neurochemistry, vol. 93, no. 4, pp. 953-962, 2005.

[12] P. Bermejo, S. Martín-Aragón, J. Benedí et al., "Peripheral levels of glutathione and protein oxidation as markers in the development of Alzheimer's disease from Mild Cognitive Impairment," Free Radical Research, vol. 42, no. 2, pp. 162-170, 2008.

[13] C. E. Teunissen, J. de Vente, H. W. M. Steinbusch, and C. De Bruijn, "Biochemical markers related to Alzheimer's dementia in serum and cerebrospinal fluid," Neurobiology of Aging, vol. 23, no. 4, pp. 485-508, 2002.

[14] D. Pratico, C. M. Clark, V. M. Lee, J. Q. Trojanowski, J. Rokach, and G. A. FitzGerald, "Increased 8,12-iso-iPF $2 \alpha-\mathrm{VI}$ in Alzheimer's disease: correlation of a noninvasive index of lipid peroxidation with disease severity," Annals of Neurology, vol. 48, no. 5, pp. 809-812, 2000.

[15] L. Migliore, I. Fontana, R. Colognato, F. Coppede, G. Siciliano, and L. Murri, "Searching for the role and the most suitable biomarkers of oxidative stress in Alzheimer's disease and in other neurodegenerative diseases," Neurobiology of Aging, vol. 26, no. 5, pp. 587-595, 2005.

[16] S. Martín-Aragón, P. Bermejo-Bescós, J. Benedí et al., "Metalloproteinase's activity and oxidative stress in mild cognitive impairment and Alzheimer's disease," Neurochemical Research, vol. 34, no. 2, pp. 373-378, 2009.

[17] L. L. Torres, N. B. Quaglio, G. T. de Souza et al., "Peripheral oxidative stress biomarkers in mild cognitive impairment and Alzheimer's disease," Journal of Alzheimer's Disease, vol. 26, no. 1, pp. 59-68, 2011.

[18] I. Fridovich, "Superoxide radical and superoxide dismutases," Annual Review of Biochemistry, vol. 64, pp. 97-112, 1995.

[19] R. A. Weisiger and I. Fridovich, "Mitochondrial superoxide simutase. Site of synthesis and intramitochondrial localization," The Journal of Biological Chemistry, vol. 248, no. 13, pp. 47934796, 1973.

[20] I. Ceballos-Picot, "Transgenic mice overexpressing copper-zinc superoxide dismutase: a model for the study of radical mechanisms and aging," Comptes Rendus des Seances de la Societe de Biologie et de Ses Filiales, vol. 187, no. 3, pp. 308-323, 1993.

[21] M. Dumont, E. Wille, C. Stack, N. Y. Calingasan, M. F. Beal, and M. T. Lin, "Reduction of oxidative stress, amyloid deposition, and memory deficit by manganese superoxide dismutase overexpression in a transgenic mouse model of Alzheimer's disease," The FASEB Journal, vol. 23, no. 8, pp. 2459-2466, 2009.

[22] P. Sompol, W. Ittarat, J. Tangpong et al., "A neuronal model of Alzheimer's disease: an insight into the mechanisms of oxidative 
stress-mediated mitochondrial injury," Neuroscience, vol. 153, no. 1, pp. 120-130, 2008.

[23] A. Cimini, S. Moreno, M. D’Amelio et al., "Early biochemical and morphological modifications in the brain of a transgenic mouse model of Alzheimer's disease: a role for peroxisomes," Journal of Alzheimer's Disease, vol. 18, no. 4, pp. 935-952, 2009.

[24] D. L. Marcus, J. A. Strafaci, and M. L. Freedman, "Differential neuronal expression of manganese superoxide dismutase in Alzheimer's disease," Medical Science Monitor, vol. 12, no. 1, pp. BR8-BR14, 2006.

[25] M. A. Ansari and S. W. Scheff, "Oxidative stress in the progression of Alzheimer disease in the frontal cortex," Journal of Neuropathology and Experimental Neurology, vol. 69, no. 2, pp. 155-167, 2010.

[26] L. Esposito, J. Raber, L. Kekonius et al., "Reduction in mitochondrial superoxide dismutase modulates Alzheimer's disease-like pathology and accelerates the onset of behavioral changes in human amyloid precursor protein transgenic mice," Journal of Neuroscience, vol. 26, no. 19, pp. 5167-5179, 2006.

[27] Y.-H. Wei and H.-C. Lee, "Oxidative stress, mitochondrial DNA mutation, and impairment of antioxidant enzymes in aging," Experimental Biology and Medicine, vol. 227, no. 9, pp. 671-682, 2002.

[28] J. S. Rosenblum, N. B. Gilula, and R. A. Lerner, "On signal sequence polymorphisms and diseases of distribution," Proceedings of the National Academy of Sciences of the United States of America, vol. 93, no. 9, pp. 4471-4473, 1996.

[29] A. Akyol and M. Bayramoğlu, "Photocatalytic degradation of Remazol Red F3B using ZnO catalyst," Journal of Hazardous Materials, vol. 124, no. 1-3, pp. 241-246, 2005.

[30] F. M. Farin, Y. Hitosis, S. E. Hallagan et al., "Genetic polymorphisms of superoxide dismutase in Parkinson's disease," Movement Disorders, vol. 16, no. 4, pp. 705-707, 2001.

[31] P. Gałecki, T. Pietras, and J. Szemraj, "Manganese superoxide dismutase gene (MnSOD) polimorphism in schizophrenics with tardive dyskinesia from Central Poland," Psychiatria Polska, vol. 40, no. 5, pp. 937-948, 2006.

[32] P. Gałecki, J. Smigielski, A. Florkowski, K. Bobińska, T. Pietras, and J. Szemraj, "Analysis of two polymorphisms of the manganese superoxide dismutase gene (Ile-58Thr and Ala-9Val) in patients with recurrent depressive disorder," Psychiatry Research, vol. 179, no. 1, pp. 43-46, 2010.

[33] E. M. Grasbon-Frodl, S. Kösel, O. Riess, U. Müller, P. Mehraein, and M. B. Graeber, "Analysis of mitochondrial targeting sequence and coding region polymorphisms of the manganese superoxide dismutase gene in German Parkinson disease patients," Biochemical and Biophysical Research Communications, vol. 255, no. 3, pp. 749-752, 1999.

[34] A. Hitzeroth, D. J. H. Niehaus, L. Koen, W. C. Botes, J. F. Deleuze, and L. Warnich, "Association between the MnSOD Ala-9Val polymorphism and development of schizophrenia and abnormal involuntary movements in the Xhosa population," Progress in Neuro-Psychopharmacology and Biological Psychiatry, vol. 31, no. 3, pp. 664-672, 2007.

[35] H. Hori, O. Ohmori, T. Shinkai et al., "Manganese superoxide dismutase gene polymorphism and schizophrenia: relation to tardive dyskinesia," Neuropsychopharmacology, vol. 23, no. 2, pp. 170-177, 2000.

[36] K. Krapfenbauer, E. Engidawork, N. Cairns, M. Fountoulakis, and G. Lubec, "Aberrant expression of peroxiredoxin subtypes in neurodegenerative disorders," Brain Research, vol. 967, no. 12, pp. 152-160, 2003.
[37] S. Shimoda-Matsubayashi, H. Matsumine, T. Kobayashi, Y. Nakagawa-Hattori, Y. Shimizu, and Y. Mizuno, "Structural dimorphism in the mitochondrial targeting sequence in the human manganese superoxide dismutase gene. A predictive evidence for conformational change to influence mitochondrial transport and a study of allelic association in Parkinson's disease," Biochemical and Biophysical Research Communications, vol. 226, no. 2, pp. 561-565, 1996.

[38] M. Singh, A. J. Khan, P. P. Shah, R. Shukla, V. K. Khanna, and D. Parmar, "Polymorphism in environment responsive genes and association with Parkinson disease," Molecular and Cellular Biochemistry, vol. 312, no. 1-2, pp. 131-138, 2008.

[39] H. W. Wiener, R. T. Perry, Z. Chen, L. E. Harrell, and R. C. P. Go, "A polymorphism in SOD2 is associated with development of Alzheimer's disease," Genes, Brain and Behavior, vol. 6, no. 8, pp. 770-775, 2007.

[40] M. Ventriglia, L. Bocchio Chiavetto, C. Scassellati et al., "Lack of association between MnSOD gene polymorphism and sporadic Alzheimer's Disease," Aging Clinical and Experimental Research, vol. 17, no. 6, pp. 445-448, 2005.

[41] K. Kitagawa, M. Matsumoto, K. Kuwabara et al., "Protective effect of apolipoprotein $\mathrm{E}$ against ischemic neuronal injury is mediated through antioxidant action," Journal of Neuroscience Research, vol. 68, no. 2, pp. 226-232, 2002.

[42] R. K. Tangirala, D. Praticó, G. A. FitzGerald et al., "Reduction of isoprostanes and regression of advanced atherosclerosis by apolipoprotein E," The Journal of Biological Chemistry, vol. 276, no. 1, pp. 261-266, 2001.

[43] M. Miyata and J. D. Smith, "Apolipoprotein E allele-specific antioxidant activity and effects on cytotoxicity by oxidative insults and $\beta$-amyloid peptides," Nature Genetics, vol. 14, no. 1, pp. 55-61, 1996.

[44] C. Ramassamy, D. Averill, U. Beffert et al., "Oxidative insults are associated with apolipoprotein E genotype in Alzheimer's disease brain," Neurobiology of Disease, vol. 7, no. 1, pp. 23-37, 2000.

[45] Y. Ihara, T. Hayabara, K. Sasaki, R. Kawada, Y. Nakashima, and S. Kuroda, "Relationship between oxidative stress and apoE phenotype in Alzheimer's disease," Acta Neurologica Scandinavica, vol. 102, no. 6, pp. 346-349, 2000.

[46] S. Chang, T. R. Ma, R. D. Miranda, M. E. Balestra, R. W. Mahley, and Y. Huang, "Lipid- and receptor-binding regions of apolipoprotein E4 fragments act in concert to cause mitochondrial dysfunction and neurotoxicity," Proceedings of the National Academy of Sciences of the United States of America, vol. 102, no. 51, pp. 18694-18699, 2005.

[47] G. E. Gibson, V. Haroutunian, H. Zhang et al., "Mitochondrial damage in Alzheimer's disease varies with apolipoprotein $\mathrm{E}$ genotype," Annals of Neurology, vol. 48, no. 3, pp. 297-303, 2000.

[48] L. Jofre-Monseny, A.-M. Minihane, and G. Rimbach, "Impact of apoE genotype on oxidative stress, inflammation and disease risk," Molecular Nutrition and Food Research, vol. 52, no. 1, pp. 131-145, 2008.

[49] M. F. Martínez, X. E. Martín, L. G. Alcelay et al., “The COMT Val158 met polymorphism as an associated risk factor for Alzheimer disease and mild cognitive impairment in APOE 4 carriers," BMC Neuroscience, vol. 10, article 125, 2009.

[50] S. Wilton and L. Lim, "Rapid identification of ApoE alleles by multiple-single-strand conformation polymorphism (SSCP) analysis," Trends in Genetics, vol. 11, no. 9, p. 341, 1995.

[51] M. Alvarez-Alvarez, L. Galdos, M. Fernández-Martínez et al., "5-Hydroxytryptamine 6 receptor $(5-\mathrm{HT} 6)$ receptor and 
apolipoprotein E (ApoE) polymorphisms in patients with Alzheimer's disease in the Basque Country," Neuroscience Letters, vol. 339, no. 1, pp. 85-87, 2003.

[52] S. W. Guo and E. A. Thompson, "Performing the exact test of Hardy-Weinberg proportion for multiple alleles," Biometrics, vol. 48, no. 2, pp. 361-372, 1992.

[53] I. Menashe, P. S. Rosenberg, and B. E. Chen, "PGA: power calculator for case-control genetic association analyses," $B M C$ Genetics, vol. 9, article 36, 2008.

[54] P. I. Moreira, M. S. Santos, C. R. Oliveira et al., "Alzheimer disease and the role of free radicals in the pathogenesis of the disease," CNS and Neurological Disorders-Drug Targets, vol. 7, no. 1, pp. 3-10, 2008.

[55] R. Sultana and D. A. Butterfield, "Role of oxidative stress in the progression of Alzheimer's disease," Journal of Alzheimer's Disease, vol. 19, no. 1, pp. 341-353, 2010.

[56] R. Sultana and D. A. Butterfield, "Role of oxidative stress in the progression of Alzheimer's disease," Journal of Alzheimer's Disease, vol. 19, no. 1, pp. 341-353, 2010.

[57] X. Zhu, B. Su, X. Wang, M. A. Smith, and G. Perry, "Causes of oxidative stress in Alzheimer disease," Cellular and Molecular Life Sciences, vol. 64, no. 17, pp. 2202-2210, 2007.

[58] G. M. Peavy, "The effects of stress and APOE genotype on cognition in older adults," The American Journal of Psychiatry, vol. 165, no. 11, pp. 1376-1378, 2008.

[59] A. Sutton, A. Imbert, A. Igoudjil et al., "The manganese superoxide dismutase Ala16Val dimorphism modulates both mitochondrial import and mRNA stability," Pharmacogenetics and Genomics, vol. 15, no. 5, pp. 311-319, 2005.

[60] A. Sutton, H. Khoury, C. Prip-Buus, C. Cepanec, D. Pessayre, and F. Degoul, "The Ala16Val genetic dimorphism modulates the import of human manganese superoxide dismutase into rat liver mitochondria," Pharmacogenetics, vol. 13, no. 3, pp. 145157, 2003.

[61] D. A. Bennett, R. S. Wilson, J. A. Schneider et al., "Natural history of mild cognitive impairment in older persons," Neurology, vol. 59, no. 2, pp. 198-205, 2002.

[62] L. S. Elias-Sonnenschein, W. Viechtbauer, I. H. G. B. Ramakers, F. R. J. Verhey, and P. J. Visser, "Predictive value of APOEepsilon4 allele for progression from MCI to AD-type dementia: a meta-analysis," Journal of Neurology, Neurosurgery and Psychiatry, vol. 82, no. 10, pp. 1149-1156, 2011.

[63] C. Tatsuoka, H. Tseng, J. Jaeger et al., "Modeling the heterogeneity in risk of progression to Alzheimer's disease across cognitive profiles in mild cognitive impairment," Alzheimer's Research \& Therapy, vol. 5, no. 2, article 14, 2013. 


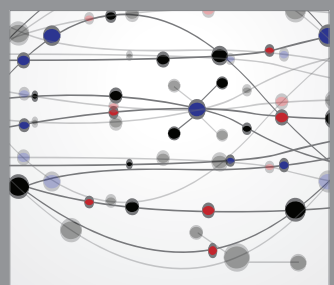

The Scientific World Journal
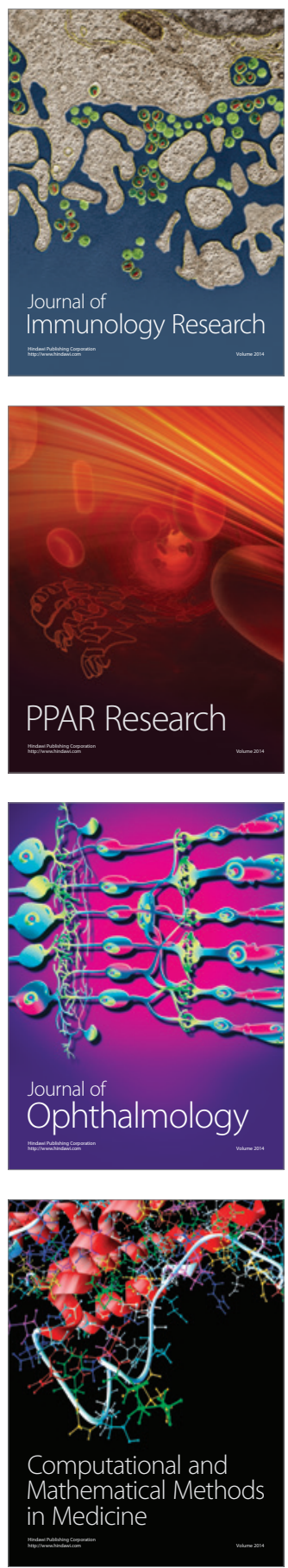

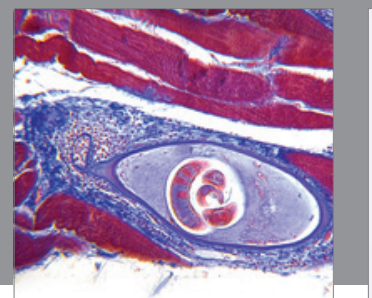

Gastroenterology

Research and Practice
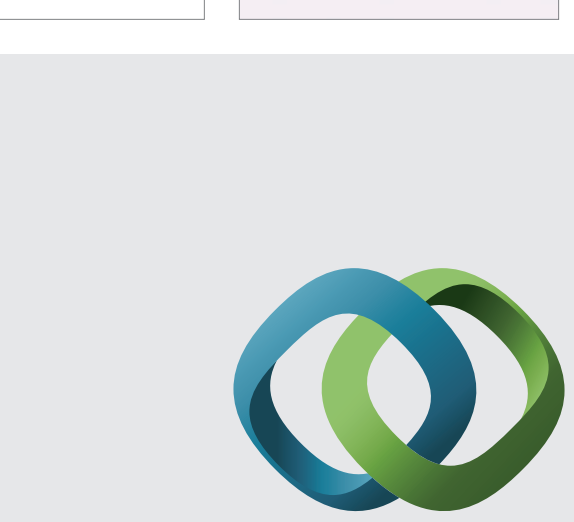

\section{Hindawi}

Submit your manuscripts at

http://www.hindawi.com
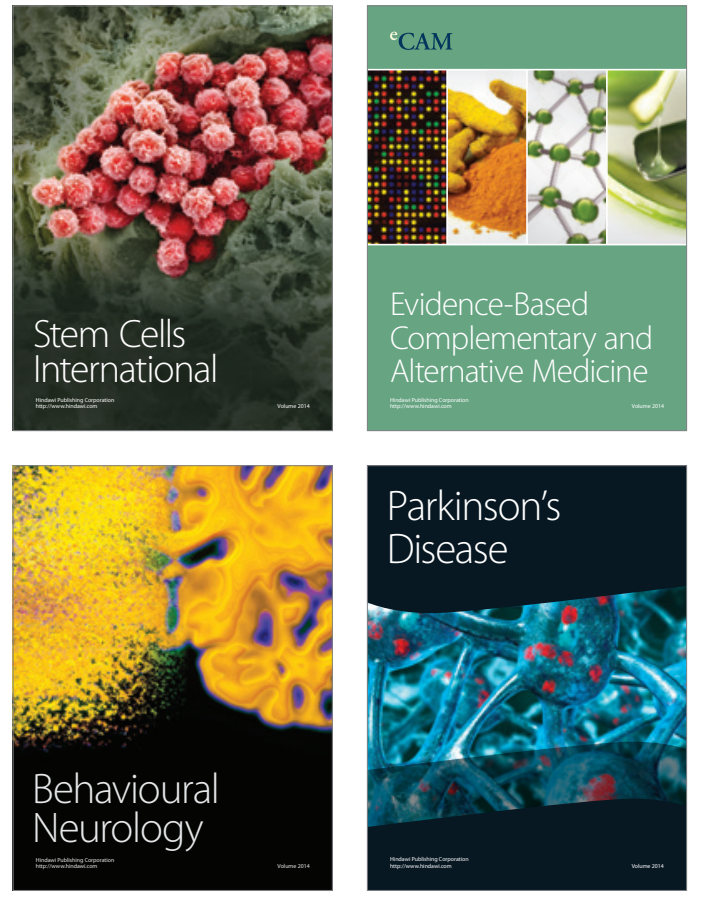
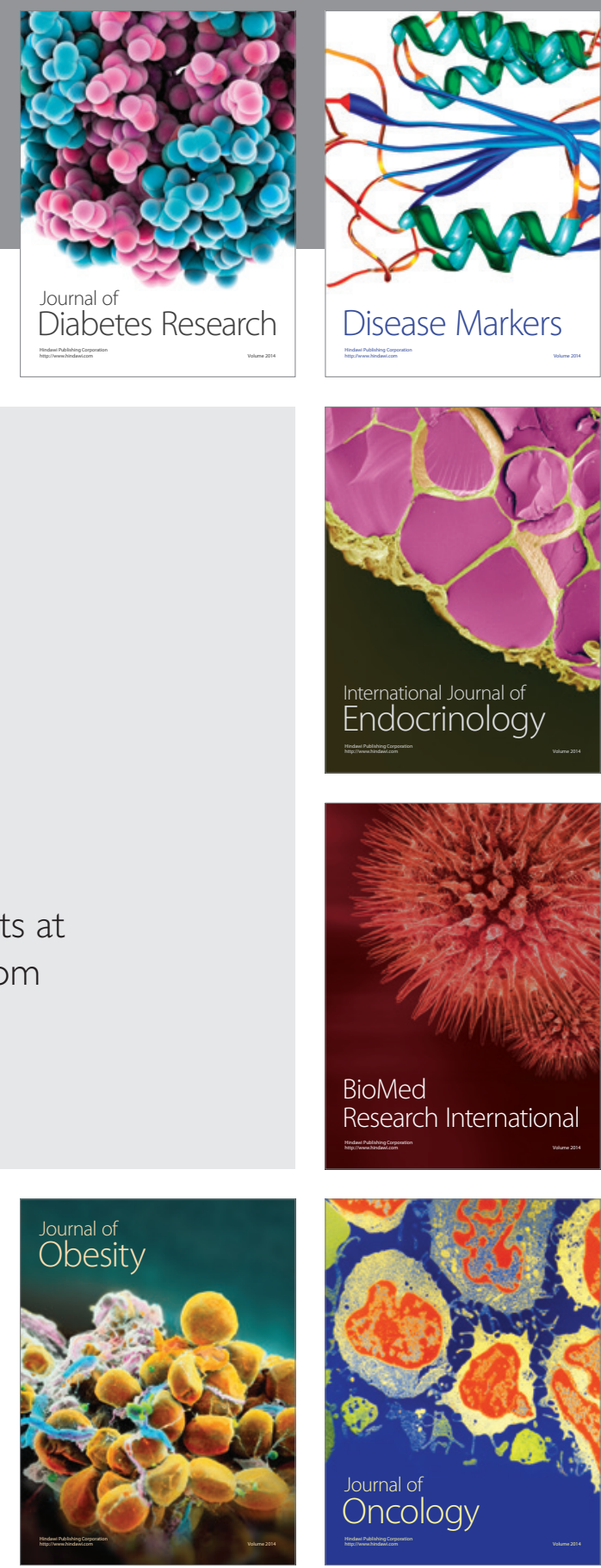

Disease Markers
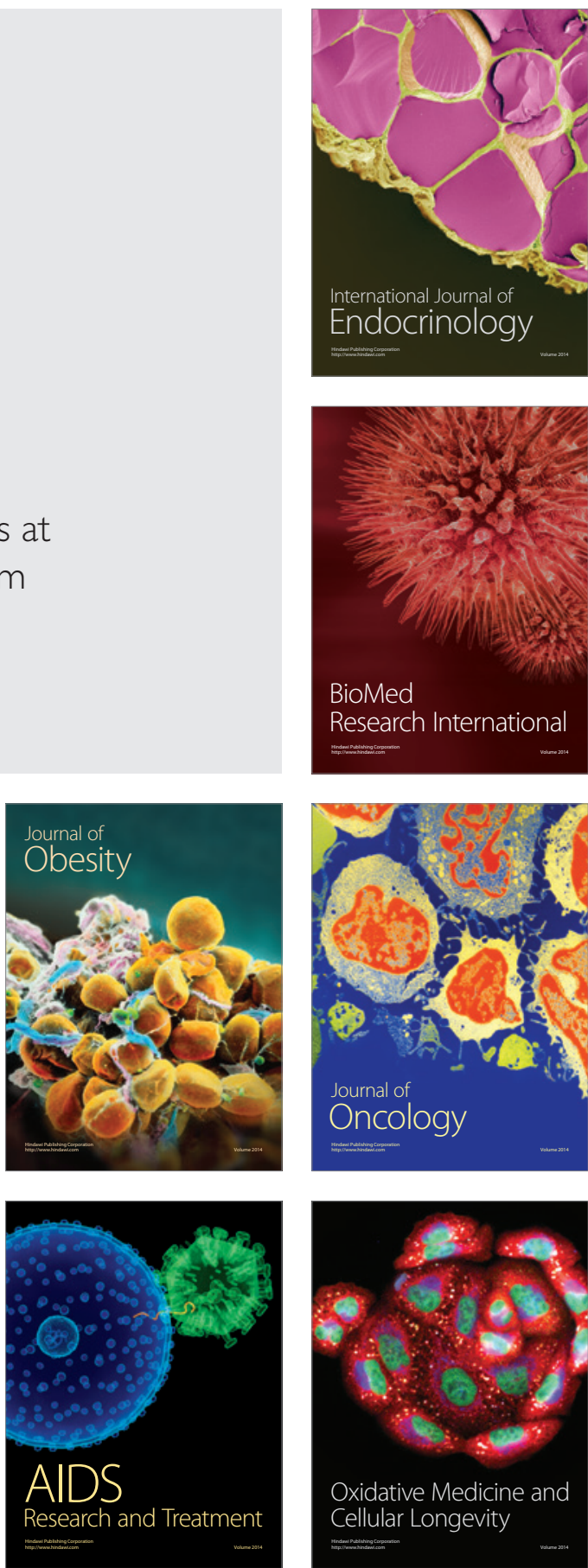